\title{
Virtual Prototype Simulation for Vibration Analysis with Optimum Dumping Characterization under High Impact Shovel Loading Conditions
}

\author{
Danish Ali $^{1}$, Samuel Frimpong ${ }^{2 *}$ \\ ${ }^{I}$ Research Assistant, Mining \& Nuclear Engineering Dept., Missouri $S$ \& T, Rolla MO, USA \\ ${ }^{2}$ Professorand Robert H. Quenon Endowed Chair, Mining \& Nuclear Engineering Dept., Missouri S \& T, Rolla \\ MO, USA
}

*Corresponding Author:Samuel Frimpong, Professorand Robert H. Quenon Endowed Chair, Mining \& Nuclear Engineering Dept., Missouri S \& T, Rolla MO, USA

\begin{abstract}
Large capacity shovels loading dump trucks with material in excess of 100 tons generates large dynamic impact forces results in high frequency shock waves, that in turn generates severe truck vibrations, and exposes the truck operator to significantly high whole body vibration levels and therefore compromises the health and the safety of operators. Previous studies have indicated a significant decrease in the dynamic impact force generated due to the gravity dumping of material into a CAT 793D dump truck by P\&H 4100XPC shovel. However, none of those studies have shown whether or not the reduction in impact force at the truck body actually translates into a reduction in the vibration levels at the operator's seat. Therefore, in current research work, 3D virtual prototype for CAT793D has been used to conduct a detailed vibration analysis using MSC ADAMS to explore the effects of reported impulse force reductions results, on the operator's WBV exposures. Analysis shocwed that as the dumping height is reduced to 7.33, 6.33, 6.00, 5.50, 5.33, 5.00 and $4.9 \mathrm{~m}$, the vibration level at the truck operator's seat reduces by 10.42, 15.51, 15.53, 15.73, 17.22, 18.85 and $19.61 \%$, respectively, as compared to the reported value of $3.56 \mathrm{~m} / \mathrm{s}^{2}$. At an optimum dumping height of $4.90 \mathrm{~m}$, the vibration level reduces from a value of $3.56 \mathrm{~m} / \mathrm{s}^{2}$ to $2.86 \mathrm{~m} / \mathrm{s}^{2}$. Therefore, current study shows that shovel dumping height optimization significantly reduces the vibration levels which improves the health and safety of dump truck operator's working under HISLO conditions.
\end{abstract}

Keywords:Virtual Prototype, Simulation, MSC ADAMS, Dumping height, HISLO, Impact force, Whole body vibrations

\section{INTRODUCTION}

In an attempt to achieve a productivity increase and in turn achieving higher economic advantage, large capacity shovels are being more widely used at surface mining operations. As large shovels are matched with large trucks/dumpers, it has resulted in high impact shovel loading operations (HISLO). When shovel load large quantity of soil/rock material (usually 100 tons or more) into the dump truck, high frequency shock waves are generated as a result of the large impact force at the truck body. These shockwaves travel through the different truck components and reaches to the operator's cabin and exposes the truck operator to those high frequency shockwaves. Such an exposure is known as whole body vibrations (WBV).

Whole body vibration significantly impacts the human health in any earth moving operation. These vibrations effects the operators' legs, spine, lower back, shoulders, arms, hands, and neck if they continue for a long period of time which is a certainty at any surface mine over a complete shift. About $37.7 \%$ of all the equipment operation accidents that occurs in surface mining operations are result of jarring/jolting that causes operator back injuries [1]. Jolting and jarring is frequently experienced by the truck operators as a shovel loads the dump truck. Therefore, with this serious vibration problem and its adverse effects on truck operators, there is a need to focus on conducting research to understand the problem and provide practical solutions to control the extent of these vibrations to be able to improve the safety and health of the earthmoving equipment operators. 
Virtual Prototype Simulation for Vibration Analysis with Optimum Dumping Characterization under High Impact Shovel Loading Conditions

Table1. ISO Specified Comfort Zones with Operator's Vibration Exposure

\begin{tabular}{|c|c|c|c|c|c|}
\hline $\begin{array}{c}\text { RMS Acceleration } \\
\text { Value (m/sec }\end{array}$ & 0.315 to 0.63 & 0.5 to 1 & 0.8 to 1.6 & 1.25 to 2.5 & $>2$ \\
\hline Level of Comfort & $\begin{array}{c}\text { Slightly } \\
\text { Uncomfortable }\end{array}$ & $\begin{array}{c}\text { Reasonably } \\
\text { Uncomfortable }\end{array}$ & Uncomfortable & $\begin{array}{c}\text { Very } \\
\text { Uncomfortable }\end{array}$ & $\begin{array}{c}\text { Hugely } \\
\text { Uncomfortable }\end{array}$ \\
\hline
\end{tabular}

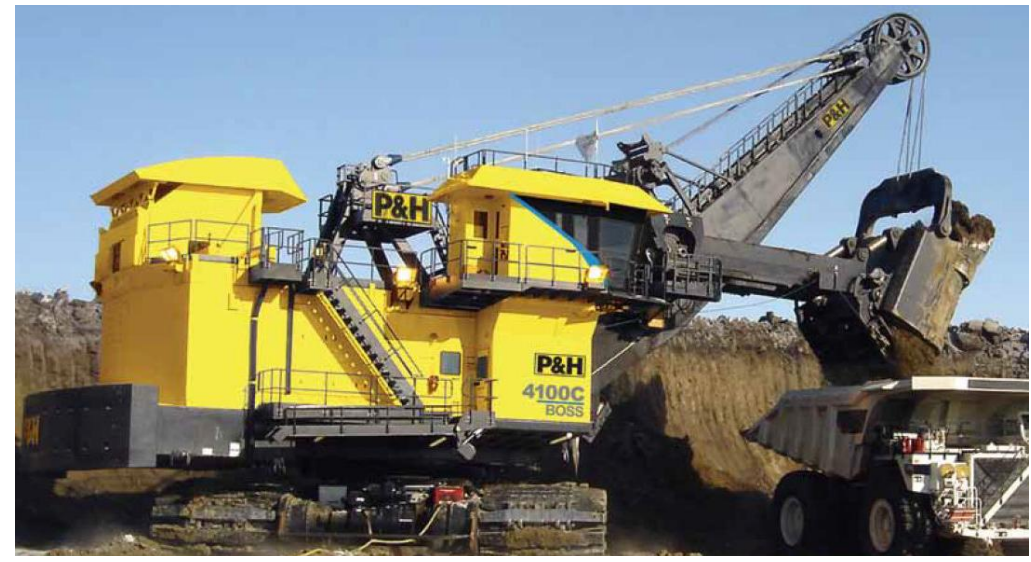

Fig1. High Impact Shovel Loading Operation (HISLO)

Recommendations, regarding the safe vibration exposure limits, beyond which the exposure could cause severe long term lower-back, shoulder, neck, etc. disorders and disabilities, have been provided by the International Standards Organization (ISO). Sections 1,2,4,5 of ISO 2631 entitles the ISO standards for the vehicular vibrations [2-5]. These sections provide the specific threshold limits for maintaining the compliance with regards to operating the vibrating equipment in a safe working environment. Table shows the long term effects of whole body vibration (WBV) on machine operators along with the corresponding vibration level for exposure during an 8-hour shift. A machine operator becomes vulnerable to shoulder, neck, etc. disabilities along with the lumbar and cervical disorders whenever the WBV exposure increases beyond the level of $1 \mathrm{~m} / \mathrm{sec}^{2}$, for an 8-hour shift [4].

Researchers in the past have either focused on investigating the vibration levels in small haulage equipment/vehicles [6-10] or vibration mitigation in military defense equipment [11, 12] by either modifying the seat ergonomics [13-15] or seat design of the equipment [14]. But then later on, Aouad \& Frimpong [16] provided a fundamental framework for a thorough understanding of the HISLO vibration problem. A comprehensive and fundamental modeling, simulation and experimental analysis of dump truck vibrations and their impact upon the operators' health and safety was provided. At first, Frimpong et al. [17] worked on the mathematics for capturing the vibration response of a material handling equipment under high-impact loading operations. Then latter Aouad \& Frimpong [16] developed a virtual simulator to capture the truck vibration levels unde HISLO conditions using MSC ADAMS (Figure 2).

In terms of providing solution to this HISLO vibration problem and developing vibration control technology for the surface mining dump trucks, Ali and Frimpong [18] carried out a fundamental research. Dynamic impact force was modeled, detailed mathematics were laid out describing the dynamics with successful testing of the developed model [19]. Latter, a 3D virtual prototype was developed using DEM in PFC3D to simulate the shovel dumping process under HISLO conditions for P\&H 4100XPC shovel loading the a CAT 793D truck [18, 19]. Detailed demonstration was provided for capturing the impact force at the truck body using the $3 \mathrm{D}$ model, therefore, eliminating the need for any physical experimentation. Virtual simulation for the optimization of shovel dumping height was done for investigating its broader impact over impact force reductions, thus providing a practical solution for the HISLO vibration problem [18, 19]. And it was concluded that the optimization of shovel dumping process where dumping height is optimized to a value of $4.90 \mathrm{~m}$, a significant reduction can be achieved (17.34\%) for impact force values at the truck body during a HISLO operation. However, the researchers didn't show whether or not that particular impact force reduction for truck surface actually translates into a meaningful reduction in RMS accelerations at the operator's seat. 
Virtual Prototype Simulation for Vibration Analysis with Optimum Dumping Characterization under High Impact Shovel Loading Conditions

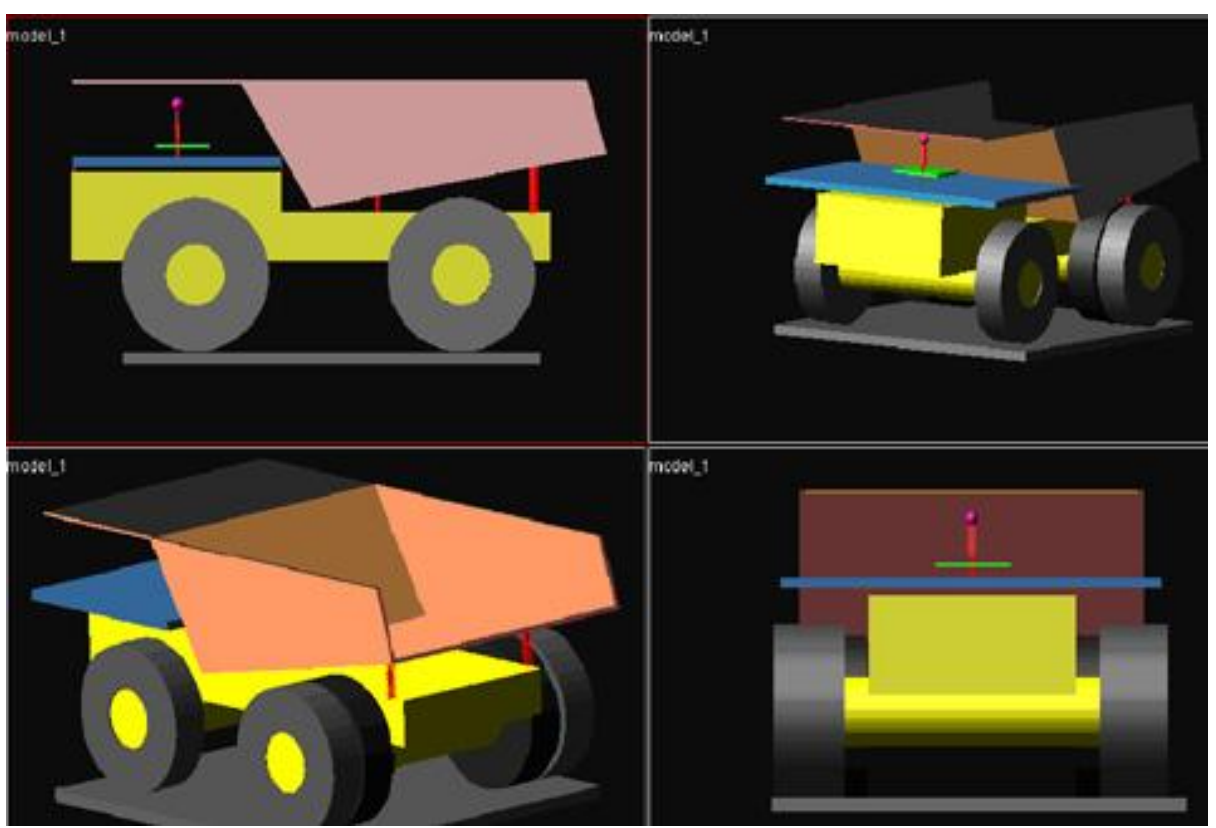

Fig2. Virtual Prototype Model for the Truck in MSC ADAMS Environment [16]

Experiments are conducted in the current study using the 3D virtual prototype model for CAT 793D to investigate the vibration amplitudes at the operator seat. RMS acceleration values will be recorded for HISLO conditions with the implementation of force model by varying the dumping height for shovel. MSC ADAMS will be utilized to carry out the virtual simulations to record the vibration levels at the seat. The work has been done to investigate whether or not the impact force reduction results reported [18] and the proposed dynamic model [19] translates into a reduction in vibration levels at the operators seat as the dumping height for the shovel-truck operation is optimized.

Note: The dumping height is considered optimized for any shovel provided that the safe clearance between the truck body outer edge and the shovel dipper's lower edge is maintained which shall prevent the truck body to undergo jolting/jarring during the shovel dumping operation.

\section{EXPERIMENTATION SETUP}

Experimentation for this study was done using the 3D virtual prototype (Figure 3) designed for CAT 793D truck. The virtual model has been used to obtain the vibration levels by implementing the dynamic force model proposed by Ali and Frimpong [19]. The 37-DOF MSC ADAMS model captures and generates the complete forced vibration analysis by computing the dynamics of the truck components with maintaining the same conditions to simulate the HILSO operation. The original virtual model was slightly modified by reversing two of the positioning coordinates, $\mathrm{y}$ and $\mathrm{z}$ directions to up - down and right - left motions, respectively. The modified model will now be used to compute the vibration levels as characterized by the RMS acceleration values, particularly for the truck's operator's seat in the $y$ - direction for visualizing the effect of reducing the dumping height on the operator's seat vibration levels. In order to obtain this objective, the approximate magnitude value of $1 \mathrm{x} 10^{6} \mathrm{~N}$ for the external impact force, was replaced with the more realistic force value obtained using the dynamic force model $[18,19]$.

Following operative asuumptions been made in order to carry out the simulation [20]:

- Seat belts are incorporated into the model by keeping the operator's body firmly attached to the truck seat.

- 3 DOFs are allowed for the truck seat including: up and down movement (y - direction), longitudinal movement left - right $(\mathrm{x}$ - direction) and yawing/rotation $(\mathrm{z}-$ direction $)$.

- The dynamic components linking the seat with the operator's cabin have been initiated in a preloaded condition for incorporating the body weight of the operator.

In ADAMS, Eigen value problem for the overall vibration system is solved using the QR (also known as the Modified version of Newton - Raphson) method. The default solver of ADAMS, which is C++, 
can't apply the QR method, so the solver has to be changed to FORTRAN. This multi degree of freedom HILSO vibration problem is then solved using the RKF 45. Before using the RKF - 45 solver, the differential algebraic equations (DAE) are converted to ordinary differential equations (ODE) by using the coordinate partitioning. RKF 45 is easier as compared to the normal Runge Kutta method but slower than the default method of MSC ADAMS/Solver.

HISLO vibration system in this study is solved with multi-body dynamics (MBD) simulation using ADAMS/View. ADAMS/Vibration was then used as a plug-in to ADAMS/Solver for the forced response analyses. A modal analysis is used to compute the Eigen values along with the Eigenvectors for the vibration model. Whereas, forced response analysis was used to witness the model response to the external excitation, which in current study is the impact force generated at the truck surface due to the shovel loading. Values for impact force, obtained by implementing the proposed force model, for varying shovel dumping heights were used as an input external force. The vibration response of the virtual prototype model is then simulated and visualized. In the end, all results including validation, simulation results, etc are post processed using ADAMS/Post Processor.
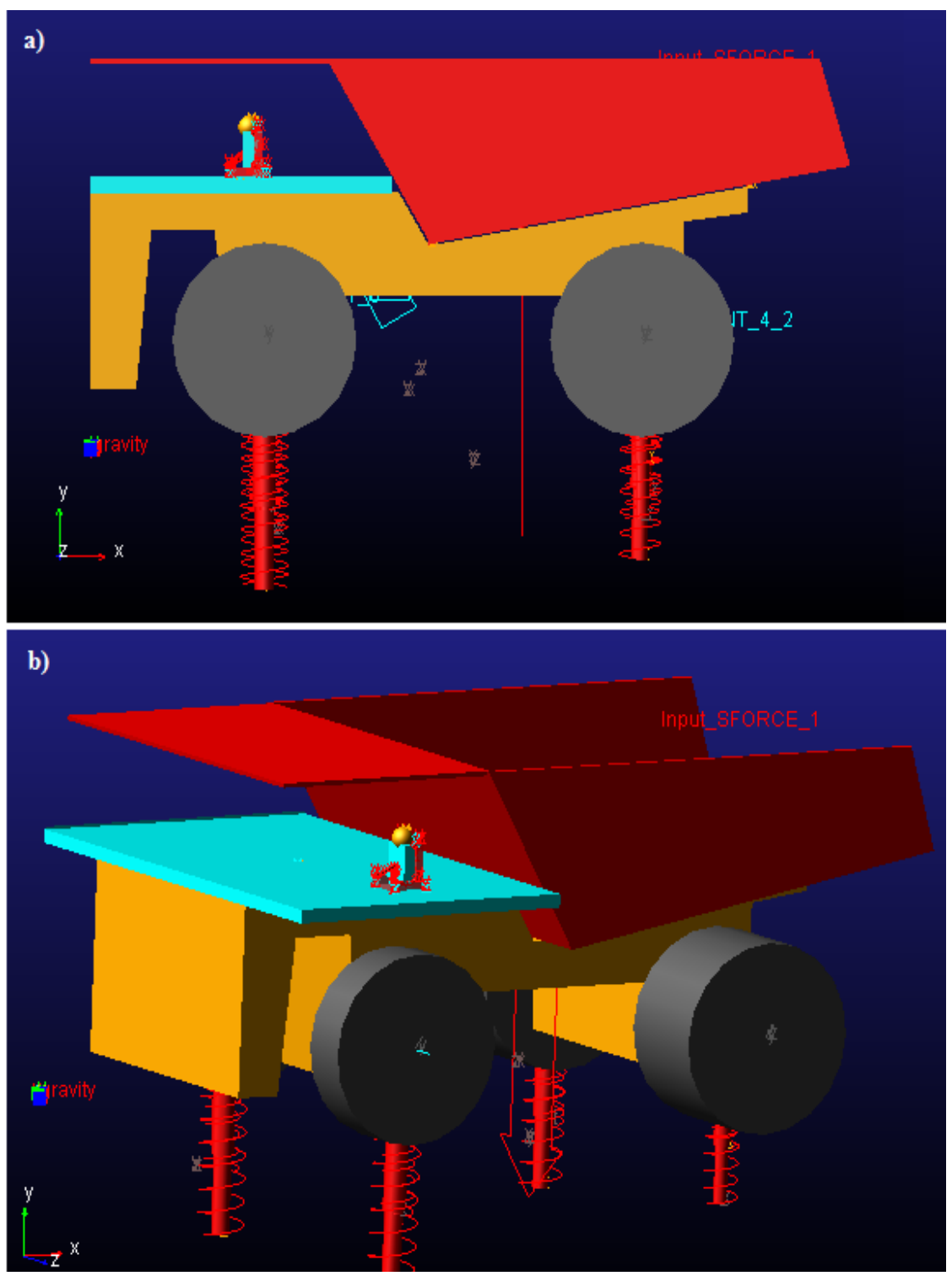

Fig3. Virtual Prototype designed for CAT 793D Truck Model and Simulated in MSC ADAMS Platform a) Solidframe Side View b) $3 D$ View

\section{RESULTS AND DISCUSSION}

The external input force was modelled using the impact force model developed by Ali and Frimpong [19] for varrying shovel dumping heights. Vibration levels at the various component of the CAT 793D dump truck were observed but the vibration levels at the truck operator seat were recorded. 
Since the external excitation impact force is acting downwards in the vertical direction, the vertical acceleration component is the dominant component in the acceleration fields. Therefore, the acceleration component in vertical direction was studied, recorded and analyzed since it is much larger than any of the other component in HISLO vibration conditions.

Vibration levels, as characterized by the RMS accelerations in the $\mathrm{y}$ - direction, at the operators seat of CAT 793D were recorded using the virtual prototype simulation in MSC ADAMS. RMS acceleration plots are displayed in figures 4, 5, 6, 7, 8, 9 and 10 for shovel dumping heights of $7.33 \mathrm{~m}$, $6.33 \mathrm{~m}, 6.00 \mathrm{~m}, 5.50 \mathrm{~m}, 5.33 \mathrm{~m}, 5.00 \mathrm{~m}$ and $4.9 \mathrm{~m}$, respectively. With the reduction in shovel dumping height, the overall component acceleration starts diminishing quickly and thus the curve begin to flatten out at an earlier time. The reason behind this being the reduction in the actual generated levels of impact force at a lower dumping height. Moreover, the large spikes in the RMS acceleration curves which indicate the highest degree of particle vibration level, are lowered with the reduced dumping height. Again it's due to fact that less impact force is produced at a lower dumping height and it definitely translates in the manner in which the shockwaves are generated, propagated and therefore resulting in reduced vibration level at truck seat. Table 2 displays the RMS acceleration results for the truck seat in $\mathrm{y}$ - direction for all the tested levels of dumping height. The recorded vibration levels were $3.189,3.008,3.007,3.000,2.947,2.889$ and $2.862 \mathrm{~m} / \mathrm{s}^{2}$ for the tested dumping heights of $7.33 \mathrm{~m}, 6.33 \mathrm{~m}, 6.00 \mathrm{~m}, 5.50 \mathrm{~m}, 5.33 \mathrm{~m}, 5.00 \mathrm{~m}$ and $4.9 \mathrm{~m}$, respectively, during the truck loading process. It can be concluded based on these results that with reducing the dumping height, the load is dropped from a smaller distance which reduces the intensity of impact force given by its magnitude at the truck bed surface which in turn causes a reduction in the vibration level at the truck operator seat. Close examination of results indicate vibration level not changing for heights corresponding to $6.33,6.00$ and $5.50 \mathrm{~m}$ even when the impact force did reduce for those dumping distances. This phenomenon could very well be explained in a way that for this particular range of impact force, the truck components primarily the truck seat vibrates within the corresponding envelope of resonance, therefore, resulting in similar values of RMS accelerations even with the changing impact force. As it can be seen, this phenomenon disappears with excitation exiting out of this particular range. There is a considerable change in the recorded RMS acceleration values which resonates with the changes in the impact force at different dumping heights outside that particular impact force range.

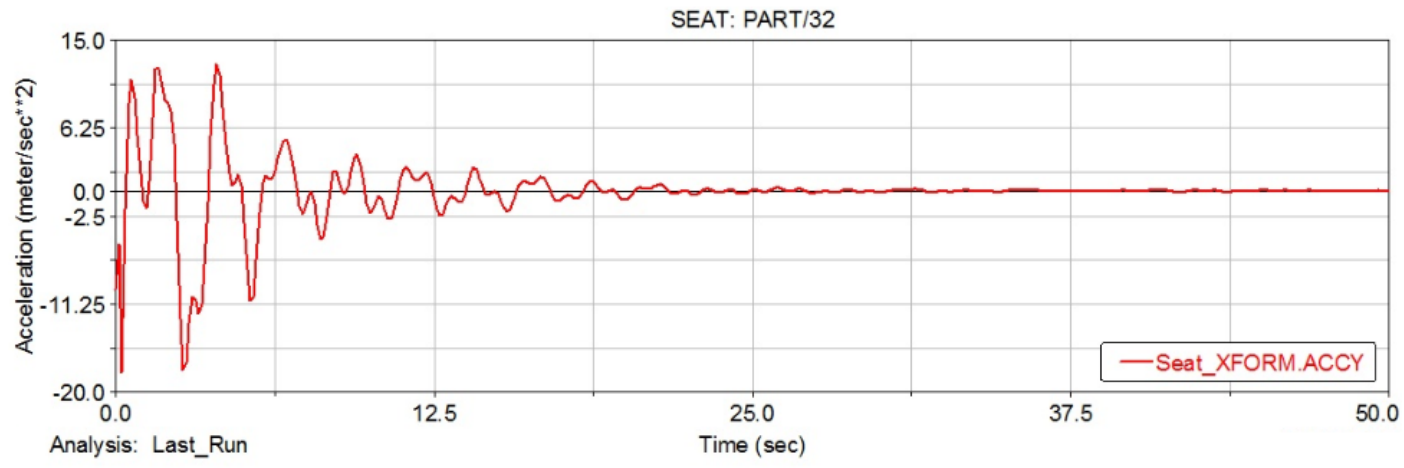

Fig4. Operator seat vibration levels in $y$-direction with keeping the dumping height at $7.33 \mathrm{~m}$

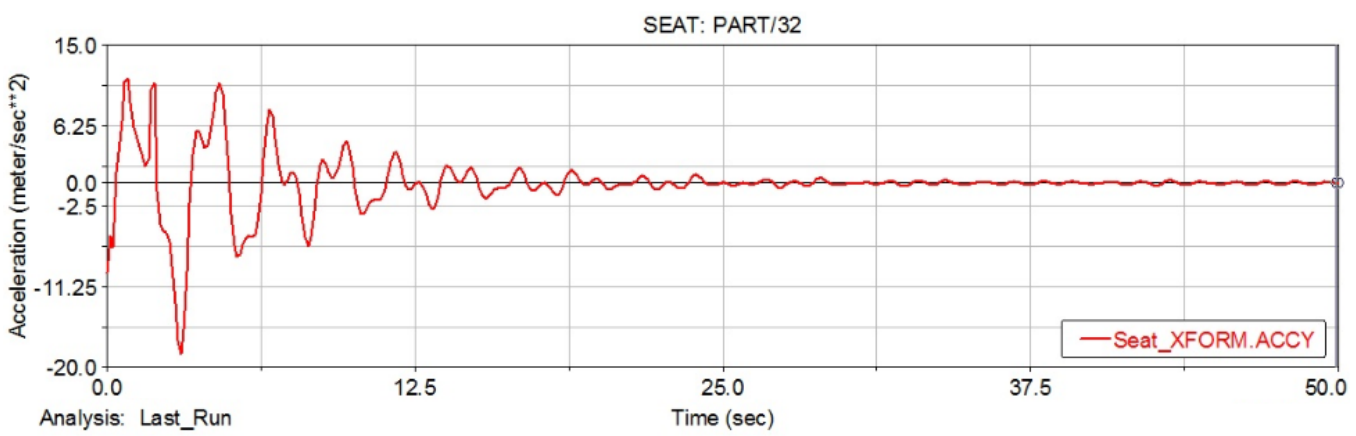

Fig5. Operator seat vibration levels in $y$-direction with keeping the dumping height at $6.33 \mathrm{~m}$ 
Virtual Prototype Simulation for Vibration Analysis with Optimum Dumping Characterization under High Impact Shovel Loading Conditions

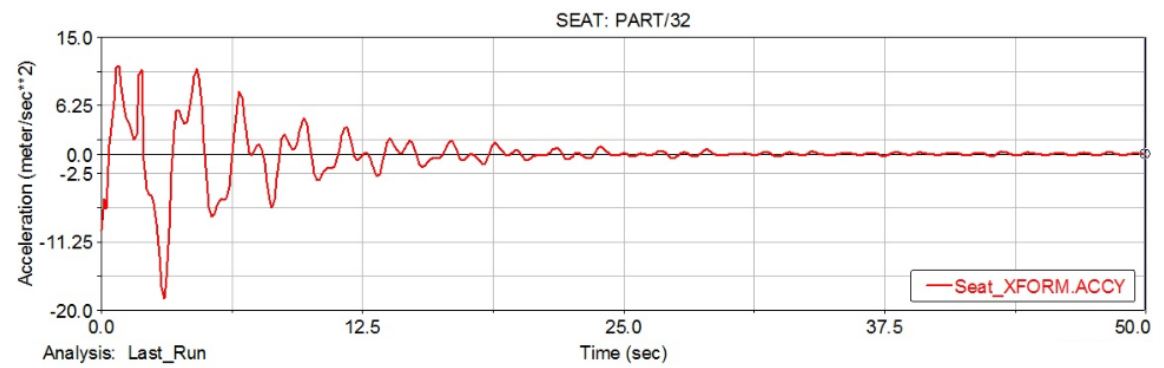

Fig6. Operator seat vibration levels in y-direction with keeping the dumping height at $6.00 \mathrm{~m}$

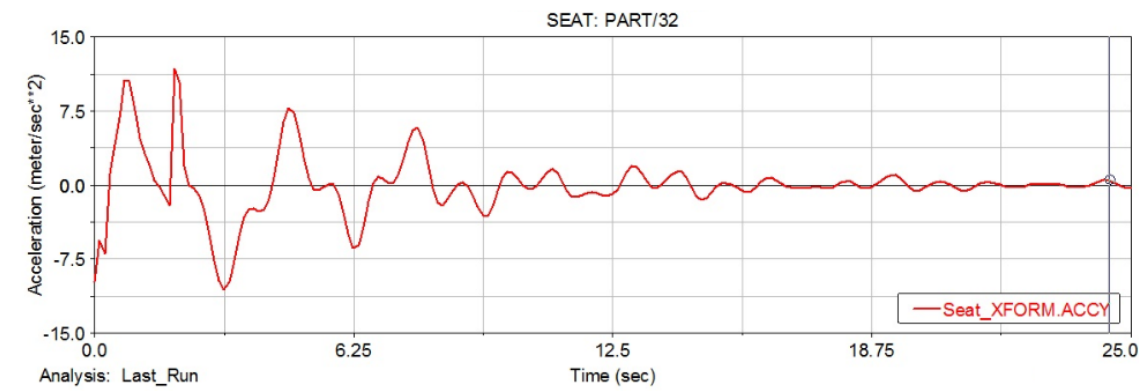

Fig7.Operator seat vibration levels in y-direction with keeping the dumping height at $5.50 \mathrm{~m}$

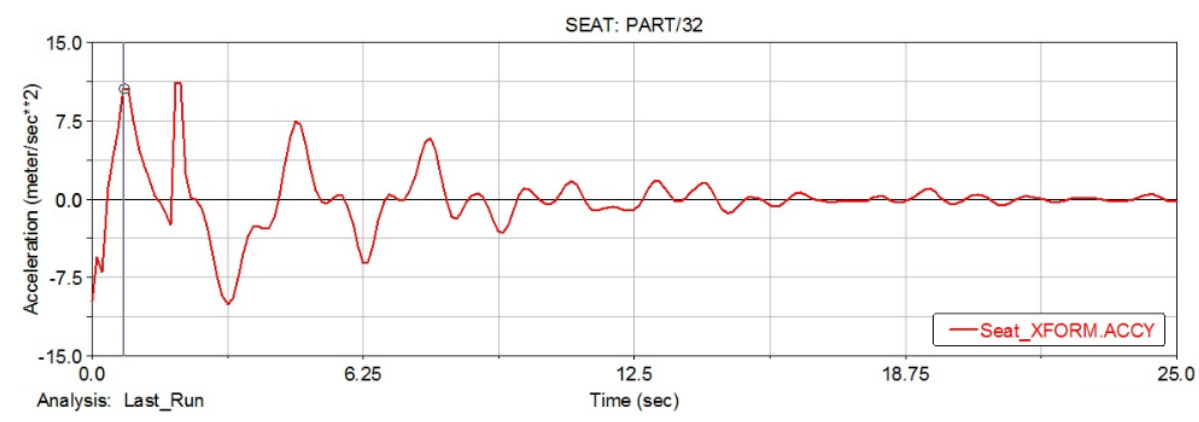

Fig8. Operator seat vibration levels in $y$-direction with keeping the dumping height at $5.33 \mathrm{~m}$

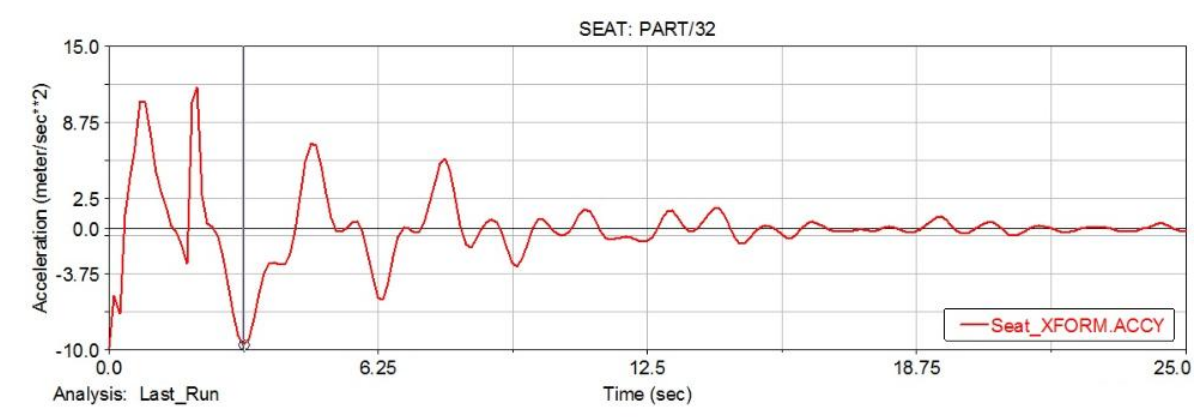

Fig9. Operator seat vibration levels in $y$-direction with keeping the dumping height at $5.00 \mathrm{~m}$

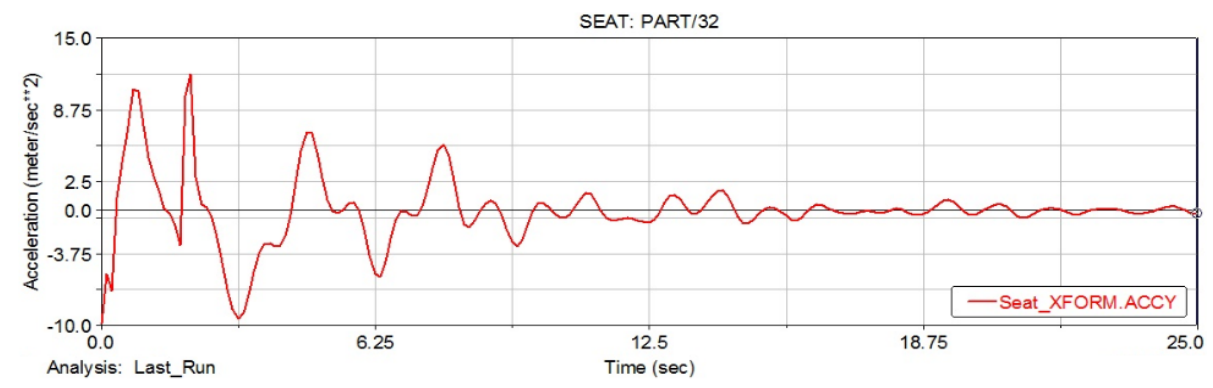

Fig10. Operator seat vibration levels in $y$-direction with keeping the dumping height at $4.90 \mathrm{~m}$ 
Virtual Prototype Simulation for Vibration Analysis with Optimum Dumping Characterization under High Impact Shovel Loading Conditions

Table2. Impact Force Magnitudes and resulting RMS Accelerations in y-direction at Operator's Seat

\begin{tabular}{|c|c|c|}
\hline $\begin{array}{c}\text { Dumping Height } \\
\left(\mathrm{H}_{\mathrm{t}}\right)\end{array}$ & $\begin{array}{c}\text { Maximum Magnitude for Impact Force } \\
\text { during } 1^{\text {st }} \text { Pass }\end{array}$ & $\begin{array}{c}\text { Vertical RMS Acceleration Recorded at } \\
\text { Operator' Seat }\end{array}$ \\
\hline$(\mathrm{m})$ & $(\mathrm{kN})$ & $\left(\mathrm{m} / \mathrm{s}^{2}\right)$ \\
\hline 7.33 & 838 & 3.189 \\
\hline 6.33 & 800 & 3.008 \\
\hline 6.00 & 775 & 3.007 \\
\hline 5.50 & 742 & 3.000 \\
\hline 5.33 & 720 & 2.947 \\
\hline 5.00 & 705 & 2.889 \\
\hline 4.90 & 692 & 2.862 \\
\hline
\end{tabular}

The reported vibration level characterized by the RMS acceleration value (up - down direction) at the truck seat was $3.56 \mathrm{~m} / \mathrm{s}^{2}[16]$. Table 3 summarizes the results describing the percent reduction in truck operator's seat vertical RMS acceleration values as compared to the reported vibration level of 3.56 $\mathrm{m} / \mathrm{s}^{2}$. Results showed a stark increase in percent reduction with a decrease in shovel dumping distance. With the shovel dumping material at an optimized distance of $4.9 \mathrm{~m}$, as determined through the discrete element simulation [18] and mathematical modeling results [19], the resulting impact force is greatly reduced and more importantly, translates into a percent reduction of $19.61 \%$ in the vibration level at the truck operator's seat.

Table3. Percent Reduction in RMS values (vertical direction) at Truck Seat

\begin{tabular}{|c|c|c|c|}
\hline \multirow{2}{*}{ Dumping Distance, $\mathrm{H}_{\mathrm{t}}(\mathrm{m})$} & \multicolumn{2}{|c|}{ Recorded RMS Acceleration $\left(\mathrm{m} / \mathrm{s}^{2}\right)$} & \multirow{2}{*}{$\%$ Difference } \\
\cline { 2 - 3 } & Results from Aouad \& Frimpong [16] & Simulation Model & \\
\hline 7.33 & 3.560 & 3.189 & 10.42 \\
\hline 6.33 & 3.560 & 3.008 & 15.51 \\
\hline 6.00 & 3.560 & 3.007 & 15.53 \\
\hline 5.50 & 3.560 & 3.000 & 15.73 \\
\hline 5.33 & 3.560 & 2.947 & 17.22 \\
\hline 5.00 & 3.560 & 2.889 & 18.85 \\
\hline 4.90 & 3.560 & 2.862 & 19.61 \\
\hline
\end{tabular}

Figures 11 and 12 graphically displays the reduction achieved in the vibration specifically at the truck operator's seat in the vertical direction with the optimization of the dumping height and the extent to which the vibration levels can be reduced in comparison to the current vibration levels, reported by Aouad \& Frimpong [16], respectively.

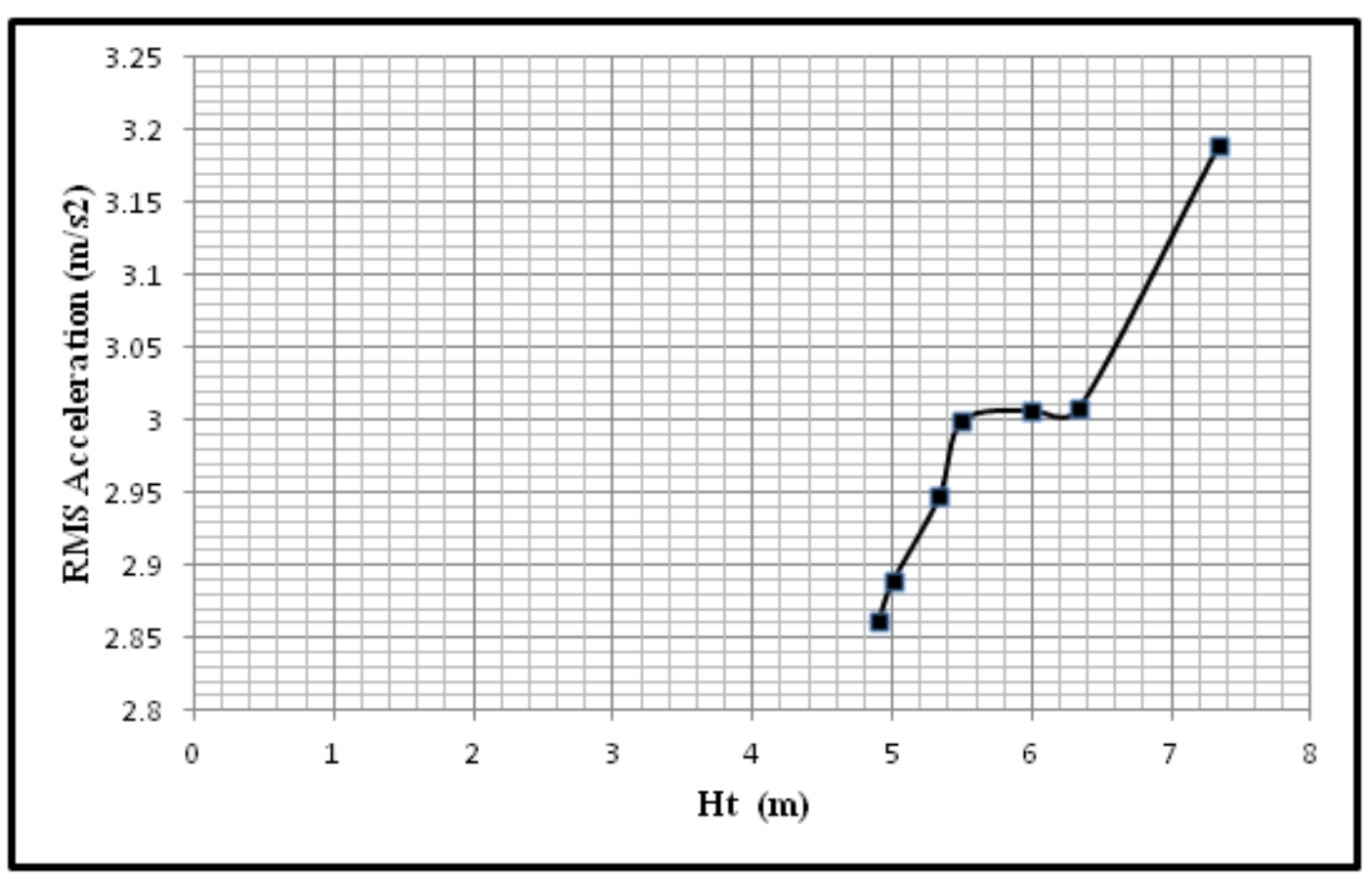

Fig11. RMS Acceleration values recorded at the operator's seat in y-direction (up - down) 
Virtual Prototype Simulation for Vibration Analysis with Optimum Dumping Characterization under High Impact Shovel Loading Conditions

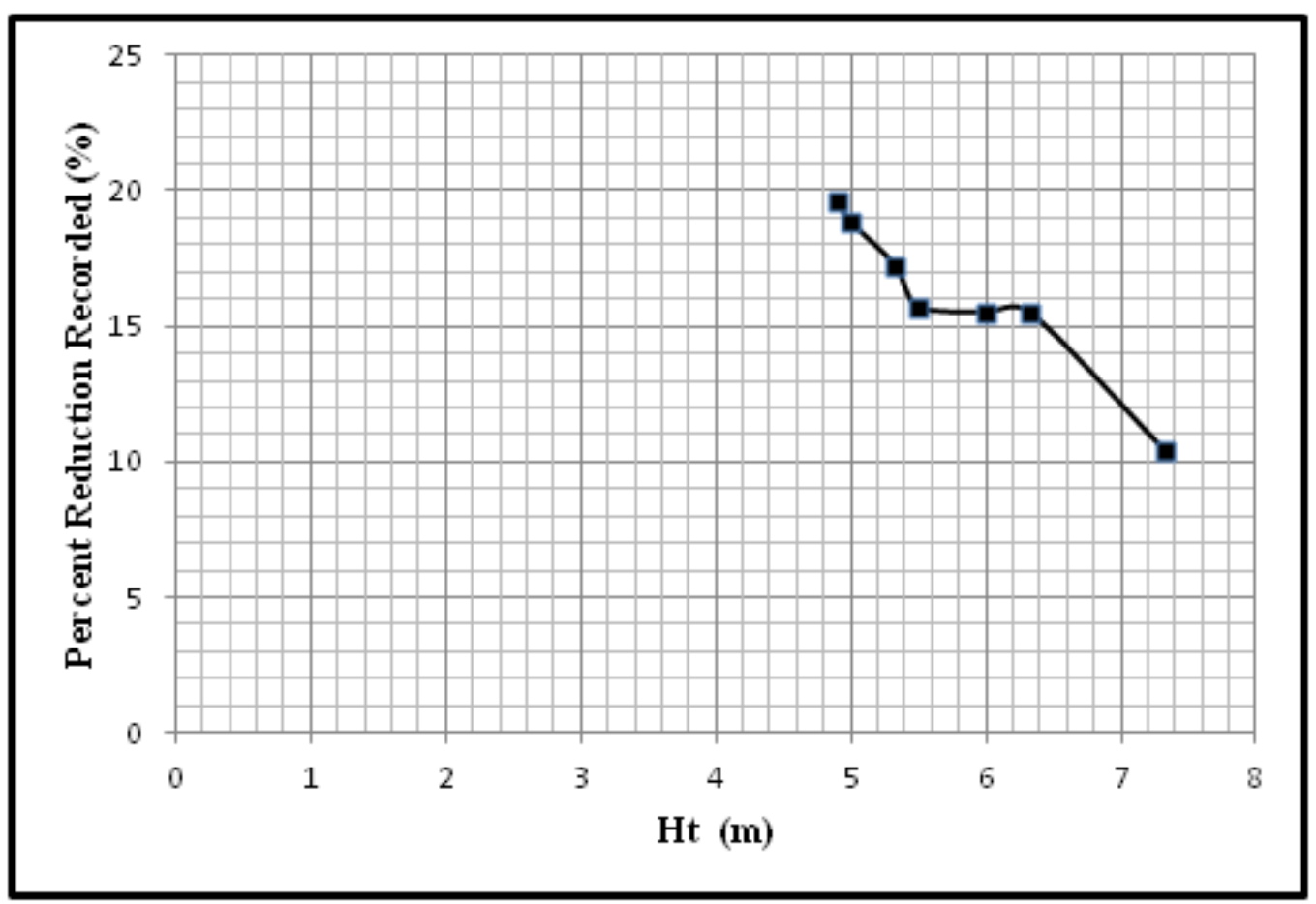

Fig12. RMS Acceleration Reduction at operators' seat in vertical (up - down) direction compared to the RMS value reported by Aouad \& Frimpong [16]

\section{CONCLUSION AND RECOMMENDATION}

Detailed vibration analysis has been carried out by implementing the developed impact force model in MSC ADAMS. Experimentation was done by virtually simulating the HILSO operation using the 37DOF prototype model for CAT 793D.

The RMS acceleration (vertical direction) results, for the operator's seat, were recorded through the simulation for varying shovel dumping heights. The simulation results have been compared with the previously determined value, for non-optimized operation, of $3.56 \mathrm{~m} / \mathrm{s}^{2}$.The analysis showed that a significant percent reduction (19.61\%) in vibration level at the truck operator seat can be achieved with the optimization of the dumping height to a value of $4.9 \mathrm{~m}$.

This research contributes significantly especially by developing a fundamental foundation into the subject of truck vibration mitigation. Current work signifies and illustrates how the impact force reductions at the truck body surface translates into a significant reduction in the vibration levels for large capacity dump trucks at the operator's seat. Therefore it can be concluded that vibration levels can be significantly reduced with optimizing the shovel dumping distance, which will improve the operational health and safety at a mining site under HISLO conditions.

\section{REFERENCES}

[1] Aldinger, J. A.; Kenny, J. M.; Keran CM (1995) Mobile Equipment Accidents in Surface Coal Mines. US Bur Mines, Inf Circ 942851

[2] ISO 2631 - 1 (1997) Mechanical Vibration and Shock - Evaluation of Human Exposure to Whole Body Vibration - Part 1: General Requirements. Int Organ Stand Switz

[3] 3. ISO 2631 - 4 (2001) Mechanical Vibration and Shock - Evaluation of Human Exposure to Whole Body Vibration - Part 4: Guidelines for the evaluation of the effects of Vibration and Rotational Motion on Passenger and Crew Comfort in Fixed guide way Transport Systems. Int Organ Stand Switz

[4] ISO 2631 - 5 (2004) Mechanical Vibration and Shock - Evaluation of Human Exposure to Whole Body Vibration - Part 5: Method for Evaluation of Vibration containing Multiple Shocks. Int Organ Stand Switz

[5] ISO 2631 - 2 (2003) Mechanical Vibration and Shock - Evaluation of Human Exposure to Whole Body Vibration - Part 2: Vibrations in buildings (1 Hz to $80 \mathrm{~Hz}$ ). Int Organ Stand Switz

[6] Eger T, Smets M, Grenier S (2005) Whole-Body-Vibration Exposure Experienced During the Operation of Small and Large Load-Haul-Dump Vehicles. In: 5th Canadian Rural Health Research Society Conference and the Fourth International Rural Nurses Congress. Sudbury, ON 
[7] Hoy J, Mubarak N, Nelson S, et al (2005) Whole body vibration and posture as risk factors for low back pain among forklift truck drivers. J Sound Vib 284:933-946. https://doi.org/10.1016/J.JSV.2004.07.020

[8] Wenzhang, Z.; Yi, L.; Guobiao, S.; Ligong W (2000) Study on Non-Linear Dynamic Characteristic of Vehicle Suspension Rubber Component. In: 2000 North American ADAMS User Conference. Orlando, FL, USA, pp $19-21$

[9] Kim, W.; Lee, J-W.; Kim, H-K.; Doo M-S (2001) Handling Analysis of Active Height Control System using ADAMS. In: North American MDI Users' Conference. Novi, Michigan, USA, pp 18-20

[10] Chang MK, Li YF, Huang HW (2011) Hazard of Vibration and Healthy Risk Assessment for Domestic Dump Truck Driver in Taiwan. Appl Mech Mater 52-54:186-191. https://doi.org/10.4028/www.scientific .net/AMM.52-54.186

[11] Moses RW (1997) Vertical-Tail-Buffeting Alleviation using Piezoelectric Actuators: Some results of the Actively Controlled Response of Buffet-Affected Tails (ACROBAT) program. In: SPIE. pp 87 - 98

[12] Wickramasinghe, V.; Zimcik, D.; Chen Y (2004) A Novel Adaptive Structural Impedance Control Approach to Suppress Aircraft Vibration and Noise. Pap Present RTO AVT

[13] Kittusamy NK (2002) Ergonomic Risk Factors - A study of Heavy Earthmoving Machinery Operators. ASSE Found Res $38-45$

[14] Kittusamy, N. K.; Mayton, A. G.; Jobes, C. C.; Ambrose DH (2003) N361 A Systematic Comparison of Different Seats on Shuttle Cars Used in Underground Coal Mines. In: The 32nd International Congress and Exposition on Noise Control Engineering. Seogwipo, Korea

[15] Kittusamy, N. K.; Viswanathan, M.; Jorgensen MJ (2005) Field Study to Evaluate the Effectiveness of a Continuous Passive Lumbar Motion System. In: XIX Annual International Occupational Ergonomics and Safety Conference. Las Vegas, Nevada, USA

[16] Aouad N, Frimpong S (2013) Virtual Prototype Simulation of Truck Vibrations in High-Impact Shovel Loading Operations. J Powder Met Min S1:004: https://doi.org/10.4172/2168-9806.S1-004

[17] Frimpong, S.; Galecki, G.; Chang Z (2011) Dump truck operator vibration control in high-impact shovel loading operations. Int J Mining, Reclam Environ 25:213-225

[18] Ali D, Frimpong S (2017) Virtual Simulation of High Impact Shovel Loading Operation for Optimum Dumping Characterization. J Powder Metall Min 06:1-9. https://doi.org/10.4172/2168-9806.1000149

[19] Ali D, Frimpong S (2018) Impulse force reductions and their effects on WBV exposures in high impact shovel loading operations. Int J Min Sci Technol 28:423-435. https://doi.org/10.1016/j.ijmst.2018.03.007

[20] Ali D (2016) Mechanics of impulse force reduction for mitigating dump truck vibrations under HISLO conditions. Missouri University of Science and Technology, Rolla MO, USA

Citation: Danish Ali, Samuel Frimpong, (2019)"'Virtual Prototype Simulation for Vibration Analysis with Optimum Dumping Characterization under High Impact Shovel Loading Conditions", Southeast Cameroon, International Journal of Mining Science (IJMS), 5(3), pp.14-22, DOI: http://dx.doi.org/10.20431/24549460.0503003

Copyright: () 2019 Authors. This is an open-access article distributed under the terms of the Creative Commons Attribution License, which permits unrestricted use, distribution, and reproduction in any medium, provided the original author and source are credited 